\title{
SARS-CoV-2 and COVID-19 in older adults: what we may expect regarding pathogenesis, immune responses, and outcomes
}

\author{
Janko Nikolich-Zugich • Kenneth S. Knox • Carlos \\ Tafich Rios • Bhupinder Natt • Deepta Bhattacharya • \\ Mindy J. Fain
}

Received: 26 March 2020 / Accepted: 27 March 2020 / Published online: 10 April 2020

(C) American Aging Association 2020

\begin{abstract}
SARS-CoV-2 virus, the causative agent of the coronavirus infectious disease-19 (COVID-19), is taking the globe by storm, approaching 500,000 confirmed cases and over 21,000 deaths as of March 25, 2020. While under control in some affected Asian countries (Taiwan, Singapore, Vietnam), the virus demonstrated an exponential phase of infectivity in several large countries (China in late January and February and many European countries and the USA in March), with cases exploding by 30-50,000/day in the third and fourth weeks of March, 2020. SARS-CoV-2 has proven to be particularly deadly to older adults and those with
\end{abstract}

J. Nikolich-Zugich · D. Bhattacharya

Department of Immunobiology, University of Arizona College of Medicine-Tucson, Tucson, AZ 85724, USA

J. Nikolich-Zugich $(\bowtie) \cdot$ M. J. Fain

University of Arizona Center on Aging, University of Arizona

College of Medicine-Tucson, P.O. Box 249221, 1501 N. Campbell

Ave, Tucson, AZ 8524, USA

e-mail: nikolich@arizona.edu

\section{K. S. Knox • B. Natt}

Division of Pulmonary, Allergy, Critical Care and Sleep Medicine, Department of Medicine, University of Arizona College of Medicine-Tucson, Tucson, AZ 85724, USA

\section{K. S. Knox}

Department of Medicine, University of Arizona-Phoenix, Phoenix, AZ 85004, USA

\section{T. Rios · M. J. Fain}

Division of Geriatrics, General and Palliative Medicine, Department of Medicine, University of Arizona College of Medicine-Tucson, Tucson, AZ 85724, USA certain underlying medical conditions, many of whom are of advanced age. Here, we briefly review the virus, its structure and evolution, epidemiology and pathogenesis, immunogenicity and immune, and clinical response in older adults, using available knowledge on SARS-CoV-2 and its highly pathogenic relatives MERS-CoV and SARS-CoV-1. We conclude by discussing clinical and basic science approaches to protect older adults against this disease.

Keywords COVID-19 - SARS-CoV-2 - Older adults . Care $\cdot$ Pathogenesis $\cdot$ Immunity

\section{Introduction - Pathogenic coronaviruses}

Coronaviruses (CoV) are a family of large (27.9-31 kb) positive-strand RNA viruses, divided into $\alpha, \beta, \gamma$, and $\delta$ $\mathrm{CoV}$ (Luk et al. 2019). They infect a wide range of mammals and cause a spectrum of diseases of various severities. In humans, CoV have caused diseases ranging from the common cold-like (caused by human $\mathrm{CoV}$ 229E, NL63, HKU1, and OC43) to severe respiratory diseases caused by $\beta$-coronaviruses like the severe acute respiratory syndrome (SARS)-CoV-1 (SARS-1 in the text) and Middle East respiratory syndrome (MERS)$\mathrm{CoV}$. Given that the causative agent of the current coronavirus infectious disease-19 (COVID-19), SARSCoV-2 (SARS-2 in the text) is much more similar to its two highly pathogenic cousins than to the common cold-like coronaviruses; we will liberally use these two coronaviruses as points of reference throughout the text. 
All highly pathogenic human $\mathrm{CoV}$ are found among the $\beta-\mathrm{CoV}$, with SARS- 1 and SARS- 2 belonging to the lineage $B$ (or $\beta b$, now called Sarbecovirus) and MERS belonging to the lineage $C(\beta c)$, now renamed Merbecovirus (Luk et al. 2019). Canonical structure of SARS-1 genome, as a representative of the Sarbecovirus family, includes a large 5' open reading frame (ORF) $1 \mathrm{ab}$, which takes up two-thirds of the genome and encodes two polyproteins that contains 16 nonstructural enzymes critical for viral replication. The 3' third of the genome encodes structural proteins $\mathrm{S}$ (spike), E (envelope), M (membrane), and N (nucleoprotein) and interspersed among them the ORFs encoding nonstructural and accessory proteins $3 \mathrm{a}, 3 \mathrm{~b}, 6,7 \mathrm{a}, 7 \mathrm{~b}$, and 8 (or $8 \mathrm{a}$ and $8 \mathrm{~b}$ in some isolates). Accessory proteins play a role in immune evasion and inflammation, including inhibition of type I interferons ( $3 b$ and 6), induction of apoptosis (3a, 3b, 8a), modulation of cellular DNA synthesis (6, $8 \mathrm{~b})$, induction of arms of unfolded protein response (8), stimulation of chemokine synthesis (3a, stimulates chemokine ligand 5, CCL5; and C-X-C motif chemokine ligand 8, CXCL8), and inflammation (7, activates inflammation via NF-kB and MAPK-8) (Luk et al. 2019; de Wit et al. 2016; Brian and Baric 2005). SARS-2 belongs to the same Sarbecovirus lineage and maintains the overall structure detailed above for SARS-1. However, SARS-2 exhibits high homology to recent bat $\mathrm{CoV}$ isolate RaTG13, with 97-99\% homology at ORF1ab, N and S proteins, and only $71-75 \%$ homology to other SARS-1-related CoV, $80 \%$ to SARS-1, and $50 \%$ to MERS-CoV, suggesting direct evolution from the specific lineage of bat $\mathrm{CoV}$ and not SARS-1 (Li et al. 2020a). This is further supported by a single ns 8 gene, typical of bat CoVs (Luk et al. 2019; Li et al. 2020a). SARS-2 is also showing mutations in patients ( $\mathrm{Li}$ et al. 2020a; Zhao et al. 2020), suggesting further adaptation to its (relatively new) human hosts, although coronaviruses mutate less frequently than some other RNA viruses, due to the presence of a proofreading exonuclease, encoded by the nsp14 in the long ORF. Intense research is ongoing to target different components of the SARS-2 and coronaviruses in general using antiviral drugs.

The SARS-1 epidemics started from live animal markets in Foshan, China, in late 2002, spreading through Asia and the world (Kuiken et al. 2003). Subsequent to this outbreak, SARS-related coronaviruses (SARSr$\mathrm{CoV}$ ) were isolated from horseshoe bats in the Guangdong province, leading to identification of bats as the natural reservoir of SARS-1r-CoV and, subsequently, a source of SARS-2. Initial theory that palm civet cats were the source of SARS-1 was abandoned in light of strong evidence that civets themselves got infected in live animal markets (Luk et al. 2019). SARS-1 affected 32 countries over a span of 9 months, with 8096 laboratory-confirmed cases and 774 deaths (mortality rate of nearly $10 \%$ ). MERS-CoV was first described in Saudi Arabia in 2012 (Zaki et al. 2012). MERS has been found in 27 countries, dominantly in the Middle East, and it remains endemic in many of them due to the presence of camels, believed to be a natural reservoir of a closely related virus. As of November 2019, MERS has caused 858 deaths out of 2494 laboratory-confirmed cases (mortality rate of $33 \%$ ).

The present COVID-19 epidemic caused by SARS-2 was declared pandemic in March, 2020. It dwarfed both of its highly pathogenic cousins by the number of cases, highlighting very efficient human-to-human spread (rev. in (Rothan and Byrareddy 2020)) as well as asymptomatic spread (Bai et al. 2020) possibly due to the persistence of the virus as aerosol and on various surfaces (van Doremalen et al. 2020). Due to the high extent of spread, the overall mortality of COVID-19 is already higher by more than an order of magnitude than either SARS or MERS, although current (incomplete and insufficiently reliable) data suggest somewhat lower mortality rates, that appear to range between $0.5-8 \%$, depending on the availability of diagnostic testing and capacity of the healthcare system. The vast majority of deaths are in adults aged 60 and above. In this short review, we will address the essential pathological, clinical, and geriatric features of SARS-2; the immune response to pathogenic $\mathrm{CoV}$; and a prospective summary on what to expect and how to protect older adults from SARS-2 by using various clinical, public health, and immunological strategies.

\section{Epidemiology and transmission of SARS-2}

Current counts show nearly 500,000 confirmed cases of COVID-19, including more than 20,000 deaths around the globe. There are more than 65,000 confirmed cases in the USA to this date. Updated live counts are available on the WHO, CDC, and Johns Hopkins websites. The largest number of confirmed cases is from China, where the first reported cases were identified in the city of Wuhan in the late November of 2019 (Wang et al. 
2020b). Investigations tracking initial confirmed cases indicated that a cluster of patients had been associated with a local food market in this city. Reports of infection then occurred in South Korea, Italy, Iran, and Japan. Initial reports from these countries showed recent travel or close contact to patients that had traveled to China. This was followed by local spread from person to person (Guan et al. 2020). To date, China has more than 80,000 confirmed infections but has largely stemmed the surge using drastic social distancing measures and has experienced more imported than community-spread cases in the last 3 weeks. Italy has experienced some of the highest death rates, in line with having the second oldest population worldwide, and both Italy and the USA are expected to surpass China by total confirmed infections before April. Indeed, cases have now been identified in countries across all continents, and new cases are being reported at increasing rates compared with China.

The spread of the virus from person to person appears to occur via droplets as with other respiratory viruses. Studies have shown the virus survives in different surfaces for days and remains viable in aerosols for hours (van Doremalen et al. 2020). It is thought that person to person transmission of droplets is the main way the virus spreads, followed by aerosol and fomite transmission. It is possible that transmission occurs via fecal-oral route. Transmission of virus from asymptomatic patients has been reported, with high titers of viral load on pharyngeal samples of minimally symptomatic patients during the initial days of the disease. This is different compared with SARS and MERS, where infectivity peaks relatively later during symptomatic infection, and may account for a much larger spread of COVID-19. Still, the highest transmission rates have been reported to correlate with disease severity and are particularly pronounced in hospital settings, just like for SARS and MERS. Median incubation period is thought to be 5.1 days, while onset of symptoms has been reported up to 14 days after exposure(Lauer et al. 2020), providing basis for the length of quarantine/self-isolation.

\section{Molecular pathogenesis of coronavirus diseases and of COVID-19}

Coronaviruses utilize their $\mathrm{S}$ protein to enter host cells (rev. in (de Wit et al. 2016; Brian and Baric 2005)). In humans, for SARS-1 and 2, this entry occurs via the host cell surface enzyme angiotensin-converting enzyme 2 (ACE2) receptor. This interaction is so critically important that the human-adapted SARS-CoV infects mice poorly or not at all unless the human molecule is introduced into the mouse as a transgene (McCray et al. 2007). Indeed, molecular evolution of SARS-2 suggests that the bat virus evolved to infect humans by mutating precisely the part of the S glycoprotein necessary for receptor binding. Some other mutations have been hypothesized to be stabilizing to the virus (Angeletti et al. 2020), but it is unclear whether this relates to environmental stability and persistence on surfaces or to other parameters of stability. MERS-CoV utilizes CD26, or dipeptidyl peptidase 4, for cellular entry (de Wit et al. 2016). After the membrane fusion, viral RNA genome is uncoated and begins the translation of the long ORF, transcription of subgenomic RNAs and viral replication and assembly with structural proteins, followed by budding via the endoplasmic reticulum/Golgi intermediate compartment and release via plasma membrane fusion (rev. in (de Wit et al. 2016)).

Of the three viruses, SARS-1 is best understood with regard to pathogenesis. Following viral entry, ACE2 is downregulated, which paradoxically enhances pathology, because the presence of ACE2 has been shown to be protective against acute lung injury (Imai et al. 2005). Specifically, downregulation of ACE2 leads to compensatory overproduction of angiotensin II by ACE. Angiotensin II in turn stimulates its type 1a receptor, which increases lung vascular permeability and potentiates lung pathology (rev. in (de Wit et al. 2016)) . Therefore, both the initial and most serious prolonged injury occurs to the lungs. While the immune response is critical for the resolution of SARS-1 infection, it can also potentiate, if not drive, pathogenesis in the second phase of the disease (de Wit et al. 2016), with a paradoxical observation that viral loads often decline when the severity of the disease increases. It is not clear whether MERS follows the same course. Progression to the acute respiratory distress syndrome (ARDS) in SARS-1 has been indeed marked by upregulation of proinflammatory cytokines and chemokines, particularly interleukin- $1 \beta$ (IL-1 $\beta$ ), IL-8, IL-6, CXC-chemokine ligand 10 (CXCL10) and CC-chemokine ligand 2 (CCL2). In fact, retrospective analysis of survivors versus non-survivors revealed an early and sustained pattern of innate immune activation and soluble mediator elevation in nonsurvivors, most notably IFN- $\alpha$ and $\gamma$, CXCL10 and CCL2, and the downstream interferon-stimulated genes (SIG), without ever progressing to production of significant amounts of antibodies. Survivors, by contrast, exhibited the expected switch to antibody production 
(Cameron et al. 2008; Cameron et al. 2007). Thus, one could describe the unsuccessful immune response to SARS as "stuck in innate immunity," whereas the progression to adaptive immunity, with antibody production, strongly correlated with favorable outcomes. Studies in collaborative cross (CC) mice have so far identified a host gene Trim55 (encoding a microtubule, myosin, and titin-associated protein) as important for SARS pathogenesis; mice not possessing this molecule exhibited less lung pathology (Gralinski et al. 2015).

It is not yet clear to what extent this situation may apply to SARS-2 and COVID-19, but certain parallels exist. Overall, COVID-19 infection showed increased levels of plasma proinflammatory mediators, including IL1- $\beta$, IL1RA, IL7, IL8, IL9, IL10, basic FGF2, GCSF, GMCSF, IFN $\gamma$, IP10, MCP1, MIP1 $\alpha$, MIP1 $\beta$, PDGFB, TNF $\alpha$, and VEGFA; of these, based on the presence and levels in severe cases, IL2, IL7, IL10, GCSF, IP10, MCP1, MIP1 $\alpha$, and TNF $\alpha$ could be among mediators promoting, or marking, disease severity (rev. in (Rothan and Byrareddy 2020)). In another study, it was shown that CD4 T cells of ICU patients with COVID-19 produced more IL-6 and GM-CSF than those not requiring ICU, although the numbers, powers, and statistical treatments were not reported. As of the writing of this review, sophisticated and multidimensional measures of adaptive immunity against SARS-2 have not been reported, and it is therefore not yet possible to assess whether the "stuck in innate immunity" model applies here as well. Animal model studies will be of major help to conclusively address causal associations and to elucidate how and why adaptive immunity fails to develop in vulnerable subjects, including the elderly.

\section{Clinical manifestations and pulmonary response}

Coronaviruses cause approximately $15 \%$ of adult common colds with strains such as HCoV-OC43, HCoVNL63, and HCoV-229E being most frequently implicated. These strains, however, can cause debilitation and pneumonia in frail older adults and those with underlying immunosuppressive conditions (Greenberg 2016; Falsey et al. 1997) Additionally, in patients with underlying lung disease such as asthma and COPD, coronavirus infections are frequently implicated in exacerbations (El-Sahly et al. 2000; Stolz et al. 2019).

SARS-1 and MERS-CoV are coronaviruses which more frequently cause pneumonia and are associated with relatively high mortality compared with $\mathrm{HCoV}-229 \mathrm{E}$. Patients who seek medical attention will have symptoms similar to influenza with the prototypic fever and malaise. In those who die from severe infection, the pathologic changes in the lung are similar for both MERS and SARS1. Patients clinically have ARDS and histologically have evidence of diffuse alveolar damage (DAD) with pulmonary edema and hyaline membrane formation. Some may develop organizing pneumonia or fibrosis. Often viral inclusions are noted, in line with epithelial tropism of these viruses (Tse et al. 2004). MERS may have greater tropism for the kidney and extrapulmonary involvement (Alsaad et al. 2018; Ng et al. 2016).

COVID-19 has many clinical features similar to SARS. Although symptoms are characterized as nonspecific, they often resemble influenza more than the common cold. Predominant symptoms include fever, cough, and myalgias. Diarrhea and nausea may precede fever and respiratory symptoms. Older men and men with comorbidities are at highest risk for severe disease (Huang et al. 2020; Chen et al. 2020; Wang et al. 2020b). Mild disease may resolve without medical care or may progress to pneumonia and respiratory failure requiring hospitalization. Patients may rapidly progress to ARDS with multi-organ dysfunction and death. Leukopenia and lymphopenia are frequently noted (Huang et al. 2020; Chen et al. 2020; Wang et al. 2020b). SARS-2 may exhibit neuroinvasiveness that could affect the clinical presentation (Li et al. 2020b). Most common radiographic abnormalities on CT scan are bilateral ground glass opacities with consolidation in a peripheral, posterior, and lower lobe distribution ( $\mathrm{Zu}$ et al. 2020). Similar to SARS, a histological case of a patient who died from SARS-2 infection showed diffuse alveolar damage with hyaline membrane formation, consistent with ARDS. In contrast to peripheral lymphopenia seen in many patients, interstitial lymphocytic inflammatory infiltrates were noted (Xu et al. 2020). Some patients who recover from their pneumonia have pulmonary limitations of yet to be determined etiology. It is unclear whether older adults are disproportionately affected long term.

\section{COVID-19 and the older adult: clinical assessment and management}

Older adults are more susceptible to COVID-19 and are at significantly increased risk for morbidity and mortality (Wang et al. 2020b). Infections in older adults often 
present atypically, confounding identification and management. Contributing factors for poor health outcomes include the physiologic changes of aging; multiple agerelated comorbid conditions such as heart and lung disease, diabetes, and dementia; and associated polypharmacy. Older adults living in senior living facilities are at highest risk because of their burden of chronic illness and the impact of congregate housing. For those living alone and/or isolated, the addition of full social distancing should be particularly difficult and should be acknowledged and managed. For all older adults, however, prevention is paramount.

Fever is the most common symptom and is a key method of screening for COVID-19. However, fever response is often blunted in older adults, especially in those who are frail. An adjustment to a lower threshold (e.g., a single oral temperature of $100^{\circ} \mathrm{F}$ or two repeated oral temperatures of $>99^{\circ} \mathrm{F}$ ) (High et al. 2009) is recommended. In addition, cough and shortness of breath may present as a decline in function, such as impaired mobility or falls, or confused with an exacerbation of heart failure or COPD rather than a distinct new complaint. Older adults with dementia present unique challenges, including symptom assessment and isolation strategies. Overall, there should be a low threshold for suspicion and testing for SARS-2 in older adults. Efforts should be made to avoid the emergency room and to conduct testing and management in rapidly accessible areas with a low risk of exposure to mitigate spread and avoid overwhelming the healthcare system.

In the USA, $80 \%$ of deaths have occurred in patients aging 65 and older, and patients aging 85 and over suffer an overwhelming percentage of severe outcomes, mirroring the experience in China. Management starts with diagnostics and triaging of an older adult to appropriate level of care. A unique understanding of the tradeoffs inherent in returning to home or a senior care facility and an acute hospitalization becomes relevant. As early as possible, advance care plans should be reviewed and discussed. Patient and family should be educated regarding disease course, potential ICU interventions, and desired quality of life. The treatment plan should align with the patient's goals of care.

Although management of COVID-19 is primarily supportive, there are a number of proposed specific therapies that are being investigated (Cao et al. 2020). Older adults and their caretakers need to be aware of the constantly evolving recommendations regarding changes to their usual medications (Fang et al. 2020). In a hospitalized patient, monitoring for signs of disease progression, decompensation, and exacerbation of a chronic illness become important. Some aspects of respiratory care, otherwise considered standard therapy, are being used cautiously in COVID-19. These include the use of high-flow nasal oxygen, non-invasive positive-pressure ventilation, nebulized medications, airway clearance therapies, all with the intention of minimizing the risk of aerosolization of the virus and airborne spread. This strategy may lead to lack of certain therapeutic options for those who do not wish to be mechanically ventilated by invasive means. (COVID-19 guidelines; personal communication) Guidelines of a recovering and a recovered patient, in a "post-acute" setting, are not well established and need to be explored early as hospitals and acute care settings are expected to be overwhelmed, particularly with vulnerable older adults.

\section{Immune response to coronaviruses and SARS-CoV-2}

The immunological correlates of protection and disease for SARS-2 are still being defined in this nascent field. Yet certain lessons can be taken from the related SARS1 and other coronaviruses (Prompetchara et al. 2020). The initiation of the immune response begins through activation of pattern recognition receptors expressed by host cells. These pattern recognition receptors distinguish host from viral material by binding unique molecular determinants or by sensing inappropriate cellular locations of biomolecules. For coronaviruses, the key pattern recognition receptors are (1) Toll-like receptor 7 , which is activated by RNA in endosomes (CervantesBarragan et al. 2007; Sheahan et al. 2008); (2) RIG-I and MDA-5, which recognize cytosolic viral RNA that is double-stranded, contain a 5'-triphosphate group, and/ or lack a 5' methyl cap (Zust et al. 2011); and (3) the cGAS-STING pathway, which recognizes cytosolic DNA (Sun et al. 2012). The latter of these three groups of sensors does not directly sense material from RNA viruses but rather is likely activated by cellular damage and mitochondrial DNA release caused by viral infection (Sun et al. 2017). Upon activation, these pattern recognition sensors initiate a signaling cascade that leads to expression of type I IFN and other inflammatory cytokines. Type I IFN in turn induces an antiviral state by inducing key interferon-stimulated genes that limit 
viral replication through a variety of mechanisms (Schneider et al. 2014). For coronaviruses such as MERS-CoV, the timing of type I IFN production appears to dictate the outcome of infection in mouse models (Channappanavar et al. 2019). An early burst of type I IFN leads to protection. In contrast, a delay in IFN production causes an inability to control viral replication, leading to cellular damage of airway epithelia and the lung parenchyma and an eventual lethal inflammatory cytokine storm. The latter response often predominates in older individuals and in aged mouse models of SARS-1 infection (Rockx et al. 2009; Huang et al. 2005). Unsurprisingly, coronaviruses have evolved multiple immune evasion mechanisms to limit the early induction of type I IFN. For example, SARS-1 encodes an enzyme that adds a 2' O-methyl group to viral RNA, thereby evading detection by MDA-5 (Decroly et al. 2008; Zust et al. 2011). Similarly, coronaviruses encode proteases that antagonize STING (Sun et al. 2012). Though studies are just beginning, it seems almost certain that SARS-2 possesses similar evasion mechanisms.

Once cells of the myeloid lineage are activated through pattern recognition receptors or other damageassociated inflammatory stimuli, they can efficiently present viral peptides on MHC/HLA and begin to express costimulatory molecules that help prime T cells of the adaptive immune system. Both CD8+ T cells, which recognize peptides bound to HLA-I, and CD4+ T lymphocytes, which recognize peptide:HLA-II, are critical for viral clearance in mouse models of SARS-CoV-1 infection (Chen et al. 2010; Zhao et al. 2010). Once primed, CD8+ T cells become competent to kill virally infected cells, whereas CD4+ cells produce factors to help B cells and antibody responses as well as enhance CD8+ T cell function. Contemporaneously, B cells also become activated by cognate viral antigens through their antibody receptors. In canonical antibody responses, B cells require help from CD4+ T cells to generate germinal centers, engage in somatic hypermutation and antibody affinity maturation, and yield immunological memory. This memory is composed of cells that respond more quickly than do their naïve precursors to subsequent infections and of long-lived plasma cells that constitutively secrete antibodies. Because these antibodies preexist subsequent exposures and can provide sterilizing immunity, this humoral response is usually the best correlate of subsequent immunological protection to a variety of pathogens (Zinkernagel 2002). For this reason, vaccine efforts usually focus on eliciting an effective neutralizing antibody response that prevents infection.

For SARS-1, the most potently neutralizing antibodies target the receptor-binding domain of the $\mathrm{S}$ protein, thereby competitively inhibiting viral entry into host cells (van den Brink et al. 2005). By analogy, most initial efforts to generate subunit vaccines against SARS-2 have also focused on the corresponding S protein and its receptor-binding domain. This effort may prove to be more difficult for SARS-2 than for SARS-1. The affinity of SARS-2 S protein for its receptor ACE2 is approximately $15 \mathrm{nM}$-over 20 times tighter binding than that observed by SARS-1 S protein (Wrapp et al. 2020; Yan et al. 2020). This exceptionally tight binding approaches that of many antibodies and usually only those that have been through a prolonged affinity maturation process. Intriguingly, other neutralizing antibodies cross-react between SARS-1 and SARS-2 and appear to bind the S protein core rather than the receptor-binding domain (ter Meulen et al. 2006; Tian et al. 2020; Wang et al. 2020a). The mechanism of neutralization remains to be determined, but these preliminary data suggest that targets aside from the receptor-binding domain of $\mathrm{S}$ protein, including perhaps other SARS-2 proteins of as yet unknown significance, may warrant additional attention as vaccine candidates.

\section{Immunological basis of vulnerability to emerging infectious diseases in older adults and what to expect with SARS-2}

The immune system of older adults undergoes numerous age-related changes, collectively termed immune senescence (rev. in (Nikolich-Zugich 2018)). These changes affect many cellular and molecular elements of both the innate (Solana et al. 2006) and adaptive (Goronzy et al. 2012; Kogut et al. 2012) immune systems, as well as the coordination of the response itself in time and space (rev. in (NikolichZugich 2018)), which works effectively in young and adult individuals but deteriorates with age. A detailed description is beyond the scope of this review; however, the sum of these changes leaves older adults particularly vulnerable to new, emerging infectious diseases-exactly as seen with SARS-1, MERS, the West Nile virus (WNV), chikungunya virus (CHIKV) [REFS], and now SARS-2. 
Age-related changes begin early in life with the drop in production of new T cells. New naïve T cells are made in the thymus, a gland above the heart that is large in our childhood, but undergoes quick atrophy, called involution, so that already by the end of puberty, we get only $10 \%$ of production that we had as kids (Chinn et al. 2012). Another drop in production occurs between 40 and 50 years of age, reducing new production of naïve $\mathrm{T}$ cells to $1 \%$ (Naylor et al. 2005). A similar drop in production of naïve $\mathrm{B}$ cells occurs due to an agerelated dysfunction of the bone marrow (the site of $\mathrm{B}$ cell generation), although this occurs later in life than for T cells (Chinn et al. 2012). Naïve T and B cells made in youth are normally maintained for long periods of time in the lymph nodes (and to a lesser degree in the spleen and bone marrow for B cells). In fact, lymph nodes are in charge of both maintenance and coordination of new immune responses necessary to control viruses such as SARS-2. Lymph nodes undergo dramatic age-related changes in the final third of life, becoming less able to maintain naïve T cells (Thompson et al. 2017) and to coordinate new immune responses to emerging infections Moreover, the $\mathrm{T}$ cells that do remain do not move quickly enough to meet innate immune cells when the infection strikes (Richner et al. 2015), which could be a consequence of dysregulation in chemokines that guide $\mathrm{T}$ cell migration. Innate immune cells themselves do not get activated by infection as efficiently in mice ( $\mathrm{Li}$ et al. 2012) and humans (Metcalf et al. 2015). Once activated, both $\mathrm{T}$ and $\mathrm{B}$ cells exhibit reduced proliferation and differentiation in lymph nodes with aging. As a consequence, the immune responses to a new emerging infection are blunted, with many fewer effector cells, that are also less well armed by antimicrobial molecules, making them less effective in defending against infection as we age (Brien et al. 2009; Smithey et al. 2011).

It is certain that these same problems occur in older adults facing a COVID-19 infection. Moreover, as mentioned in the section on pathogenesis, it appears that unsuccessful responses to SARS-1 (Cameron et al. 2008; Cameron et al. 2007) (and possibly SARS-2) do not properly progress in a coordinated and effective fashion from an innate to an adaptive immune response in older adults. If so, it is to be expected that this problem will be exacerbated in older adults, where the communication between innate and adaptive immunity is known to be compromised already (Richner et al. 2015; Li et al. 2012). Studies are urgently needed to evaluate specific facets of immune dysfunction and virus (immune) pathogenesis in older adults, but all of this would be expected to result in increased morbidity and mortality in our older populations.

With regard to antiviral and immunological strategies to protect older adults from SARS-2, virus entry inhibitors are getting the early attention, and RNA replication inhibitors follow closely behind. Their validation and therapeutic/toxicity assessment is ahead of us. On the immune side, vaccine candidates are currently under clinical testing. Regardless of which candidates emerge as best for vaccine development, any final strategy will have to take into account that the most vulnerable population, the older adults, will also be the most difficult to protect by a vaccine. Indeed, it is well known that agingrelated immune defects drastically reduce the responsiveness of older adults to vaccination (Nikolich-Zugich 2018). An extremely encouraging recent development, however, is the success of the second-generation shingles vaccine against the varicella-zoster virus (VZV) in older adults (Shingrix on the US market). This vaccine contains two innate immune agonists to stimulate inflammation and cytokine release, and a single glycoprotein from VZV, and has shown $>97 \%$ efficacy in people over 65 years of age (Lal et al. 2015). It is imperative that similar strategies be incorporated in the initial design and refinement of the future vaccine against SARS2.

\section{Summary—a synthesis}

The following key points emerge from the above discussion as conclusions and questions to be addressed:

- SARS-2 has emerged as an exceptionally hardy and contagious virus.

- The brunt of its pathology is shouldered by older adults, for reasons incompletely understood.

- Current successful anti-pandemic measures have included extensive testing, contact tracking, and quarantining; where that was delayed or impossible, drastic and widespread efforts enforcing social isolation were effective.

- Prevention is the most important strategy for older adults; the added strain of social distancing on this vulnerable population should be acknowledged and managed.

- Fever and pulmonary symptoms predominate; cough and dyspnea may resolve or progress to a 
multifocal pneumonia with characteristic radiographic findings.

- Patients with severe disease may succumb to ARDS; regardless of disease severity, supportive care is the mainstay of therapy.

- Older adults often present atypically, employ a low threshold for suspicion and testing, and manage in alignment with patients' goals of care.

- Coronaviruses are recognized by TLR7, RIG-I/ MDA, and cGAS/STING innate immune sensors; all result in early IFN-I responses necessary for control of infection.

- Neutralizing antibodies directed at the spike (S) protein binding site for the ACE2 receptor are likely key to protection, although the much higher affinity of SARS-2 S protein for ACE2 (relative to SARS-1) may pose a challenge.

- Immune responses in older adults are slower, less coordinated, and less efficient, making older adults more susceptible to emerging infections

- There is evidence that immune responses to SARS-1 and suggestion that responses to SARS-2, in our most vulnerable patients, do not effectively switch from innate to adaptive (little to no antibody production) immunity, a topic needing immediate study and offering potential for immune modulation.

- Future vaccination strategies will need to elicit strong protective antibody responses in older adults, using age-appropriate adjuvants; anti-viral and immunomodulatory treatments are currently an area of intense study.

\section{Compliance with ethical standards}

Competing interests The authors declare that they have no competing interests.

\section{References}

Alsaad KO, Hajeer AH, Al Balwi M, Al Moaiqel M, Al Oudah N, Al Ajlan A, et al. Histopathology of Middle East respiratory syndrome coronovirus (MERS-CoV) infection - clinicopathological and ultrastructural study. Histopathology. 2018;72: 516-24.

Angeletti S, Benvenuto D, Bianchi M, Giovanetti M, Pascarella S, Ciccozzi M. COVID-2019: the role of the nsp2 and nsp3 in its pathogenesis. J Med Virol. 2020. https://doi.org/10.1002 /jmv.25719.
Bai Y, Yao L, Wei T, Tian F, Jin DY, Chen L, et al. Presumed asymptomatic carrier transmission of COVID-19. JAMA. 2020. https://doi.org/10.1001/jama.2020.2565.

Brian DA, Baric RS. Coronavirus genome structure and replication. Curr Top Microbiol Immunol. 2005;287:1-30.

Brien JD, Uhrlaub JL, Hirsch A, Wiley CA, Nikolich-Zugich J. Key role of T cell defects in age-related vulnerability to West Nile virus. J Exp Med. 2009;206:2735-45.

Cameron MJ, Ran L, Xu L, Danesh A, Bermejo-Martin JF, Cameron CM, et al. Interferon-mediated immunopathological events are associated with atypical innate and adaptive immune responses in patients with severe acute respiratory syndrome. J Virol. 2007;81:8692-706.

Cameron MJ, Bermejo-Martin JF, Danesh A, Muller MP, Kelvin DJ. Human immunopathogenesis of severe acute respiratory syndrome (SARS). Virus Res. 2008;133:13-9.

Cao B, Wang Y, Wen D, Liu W, Wang J, Fan G, et al. A trial of lopinavir-ritonavir in adults hospitalized with severe Covid19. N Engl J Med. 2020. https://doi.org/10.1056 /NEJMoa2001282.

Cervantes-Barragan L, Zust R, Weber F, Spiegel M, Lang KS, Akira $\mathrm{S}$, et al. Control of coronavirus infection through plasmacytoid dendritic-cell-derived type I interferon. Blood. 2007;109:1131-7.

Channappanavar R, Fehr AR, Zheng J, Wohlford-Lenane C, Abrahante JE, Mack M, et al. IFN-I response timing relative to virus replication determines MERS coronavirus infection outcomes. J Clin Invest. 2019;130:3625-39.

Chen J, Lau YF, Lamirande EW, Paddock CD, Bartlett JH, Zaki $\mathrm{SR}$, et al. Cellular immune responses to severe acute respiratory syndrome coronavirus (SARS-CoV) infection in senescent BALB/c mice: CD4+ T cells are important in control of SARS-CoV infection. J Virol. 2010;84:1289-301.

Chen N, Zhou M, Dong X, Qu J, Gong F, Han Y, et al. Epidemiological and clinical characteristics of 99 cases of 2019 novel coronavirus pneumonia in Wuhan, China: a descriptive study. Lancet. 2020;395:507-13.

Chinn IK, Blackburn CC, Manley NR, Sempowski GD. Changes in primary lymphoid organs with aging. Semin Immunol. 2012;24:309-20.

de Wit E, van Doremalen N, Falzarano D, Munster VJ. SARS and MERS: recent insights into emerging coronaviruses. Nat Rev Microbiol. 2016;14:523-34.

Decroly E, Imbert I, Coutard B, Bouvet M, Selisko B, Alvarez K, et al. Coronavirus nonstructural protein 16 is a cap- 0 binding enzyme possessing (nucleoside-2'O)-methyltransferase activity. J Virol. 2008;82:8071-84.

El-Sahly HM, Atmar RL, Glezen WP, Greenberg SB. Spectrum of clinical illness in hospitalized patients with "common cold" virus infections. Clin Infect Dis. 2000;31:96-100.

Falsey AR, McCann RM, Hall WJ, Criddle MM, Formica MA, Wycoff D, et al. The "common cold" in frail older persons: impact of rhinovirus and coronavirus in a senior daycare center. J Am Geriatr Soc. 1997;45:706-11.

Fang L, Karakiulakis G, Roth M. 'Are patients with hypertension and diabetes mellitus at increased risk for COVID-19 infection? Lancet Respir Med. 2020. https://doi.org/10.1016 /S2213-2600(20)30116-8.

Goronzy JJ, Li G, Yu M, Weyand CM. Signaling pathways in aged $\mathrm{T}$ cells - a reflection of $\mathrm{T}$ cell differentiation, cell senescence and host environment. Semin Immunol. 2012;24:365-72. 
Gralinski LE, Ferris MT, Aylor DL, Whitmore AC, Green R, Frieman MB, et al. Genome wide identification of SARS$\mathrm{CoV}$ susceptibility loci using the collaborative cross. PLoS Genet. 2015;11:e1005504.

Greenberg SB. Update on human rhinovirus and coronavirus infections. Semin Respir Crit Care Med. 2016;37:555-71.

Guan WJ, Ni ZY, Hu Y, Liang WH, Ou CQ, He JX, et al. Clinical characteristics of coronavirus disease 2019 in China. N Engl J Med. 2020. https://doi.org/10.1056/NEJMoa2002032.

High KP, Bradley SF, Gravenstein S, Mehr DR, Quagliarello VJ, Richards C, et al. Clinical practice guideline for the evaluation of fever and infection in older adult residents of longterm care facilities: 2008 update by the Infectious Diseases Society of America. Clin Infect Dis. 2009;48:149-71.

Huang KJ, Su IJ, Theron M, Wu YC, Lai SK, Liu CC, et al. An interferon-gamma-related cytokine storm in SARS patients. $\mathrm{J}$ Med Virol. 2005;75:185-94.

Huang C, Wang Y, Li X, Ren L, Zhao J, Hu Y, et al. Clinical features of patients infected with 2019 novel coronavirus in Wuhan, China. Lancet. 2020;395:497-506.

Imai Y, Kuba K, Rao S, Huan Y, Guo F, Guan B, et al. Angiotensin-converting enzyme 2 protects from severe acute lung failure. Nature. 2005;436:112-6.

Kogut I, Scholz JL, Cancro MP, Cambier JC. B cell maintenance and function in aging. Semin Immunol. 2012;24:342-9.

Kuiken T, Fouchier RA, Schutten M, Rimmelzwaan GF, van Amerongen G, van Riel D, et al. Newly discovered coronavirus as the primary cause of severe acute respiratory syndrome. Lancet. 2003;362:263-70.

Lal H, Cunningham AL, Godeaux O, Chlibek R, Diez-Domingo J, Hwang SJ, et al. Efficacy of an adjuvanted herpes zoster subunit vaccine in older adults. N Engl J Med. 2015;372: 2087-96.

Lauer SA, Grantz KH, Bi Q, Jones FK, Zheng Q, Meredith HR, et al. The incubation period of coronavirus disease 2019 (COVID-19) from publicly reported confirmed cases: estimation and application. Ann Intern Med. 2020. https://doi. org/10.7326/M20-0504.

Li G, Smithey MJ, Rudd BD, Nikolich-Zugich J. Age-associated alterations in CD8alpha+ dendritic cells impair CD8 T-cell expansion in response to an intracellular bacterium. Aging Cell. 2012;11:968-77.

Li C, Yang Y, Ren L. Genetic evolution analysis of 2019 novel coronavirus and coronavirus from other species. Infect Genet Evol. 2020a;82:104285.

Li YC, Bai WZ, Hashikawa T. The neuroinvasive potential of SARS-CoV2 may play a role in the respiratory failure of COVID-19 patients. J Med Virol. 2020b.

Luk HKH, Li X, Fung J, Lau SKP, Woo PCY. Molecular epidemiology, evolution and phylogeny of SARS coronavirus. Infect Genet Evol. 2019;71:21-30.

McCray PB Jr, Pewe L, Wohlford-Lenane C, Hickey M, Manzel L, Shi L, et al. Lethal infection of K18-hACE2 mice infected with severe acute respiratory syndrome coronavirus. J Virol. 2007;81:813-21.

Metcalf TU, Cubas RA, Ghneim K, Cartwright MJ, Grevenynghe JV, Richner JM, et al. Global analyses revealed age-related alterations in innate immune responses after stimulation of pathogen recognition receptors. Aging Cell. 2015;14:42132.
Naylor K, Li G, Vallejo AN, Lee WW, Koetz K, Bryl E, et al. The influence of age on $\mathrm{T}$ cell generation and TCR diversity. $\mathrm{J}$ Immunol. 2005;174:7446-52.

Ng DL, Al Hosani F, Keating MK, Gerber SI, Jones TL, Metcalfe $\mathrm{MG}$, et al. Clinicopathologic, immunohistochemical, and ultrastructural findings of a fatal case of Middle East respiratory syndrome coronavirus infection in the United Arab Emirates, April 2014. Am J Pathol. 2016;186:652-8.

Nikolich-Zugich J. The twilight of immunity: emerging concepts in aging of the immune system. Nat Immunol. 2018;19:10-9.

Prompetchara E, Ketloy C, Palaga T. Immune responses in COVID-19 and potential vaccines: lessons learned from SARS and MERS epidemic. Asian Pac J Allergy Immunol. 2020;38:1-9.

Richner JM, Gmyrek GB, Govero J, Tu Y, van der Windt GJW, Metcalf TU, et al. Age-dependent cell trafficking defects in draining lymph nodes impair adaptive immunity and control of west nile virus infection. PLoS Pathog. 2015;11: e1005027.

Rockx B, Baas T, Zornetzer GA, Haagmans B, Sheahan T, Frieman M, et al. Early upregulation of acute respiratory distress syndrome-associated cytokines promotes lethal disease in an aged-mouse model of severe acute respiratory syndrome coronavirus infection. J Virol. 2009;83:7062-74.

Rothan HA, Byrareddy SN. The epidemiology and pathogenesis of coronavirus disease (COVID-19) outbreak. J Autoimmun. 2020:102433.

Schneider WM, Chevillotte MD, Rice CM. Interferon-stimulated genes: a complex web of host defenses. Annu Rev Immunol. 2014;32:513-45.

Sheahan T, Morrison TE, Funkhouser W, Uematsu S, Akira S, Baric RS, et al. MyD88 is required for protection from lethal infection with a mouse-adapted SARS-CoV. PLoS Pathog. 2008;4:e1000240.

Smithey MJ, Renkema KR, Rudd BD, Nikolich-Zugich J. Increased apoptosis, curtailed expansion and incomplete differentiation of CD8(+) T-cells combine to decrease clearance of L. monocytogenes in old mice. Eur J Immunol. 2011;41: 1352-64

Solana R, Pawelec G, Tarazona R. Aging and innate immunity. Immunity. 2006;24:491-4.

Stolz D, Papakonstantinou E, Grize L, Schilter D, Strobel W, Louis R, et al. Time-course of upper respiratory tract viral infection and COPD exacerbation. Eur Respir J. 2019;54. https://doi.org/10.1183/13993003.0040.

Sun L, Xing Y, Chen X, Zheng Y, Yang Y, Nichols DB, et al. Coronavirus papain-like proteases negatively regulate antiviral innate immune response through disruption of STINGmediated signaling. PLoS One. 2012;7:e30802. https://doi. org/10.1183/13993003.0040.

Sun B, Sundstrom KB, Chew JJ, Bist P, Gan ES, Tan HC, et al. Dengue virus activates cGAS through the release of mitochondrial DNA. Sci Rep. 2017;7:3594.

ter Meulen J, van den Brink EN, Poon LL, Marissen WE, Leung CS, Cox F, et al. Human monoclonal antibody combination against SARS coronavirus: synergy and coverage of escape mutants. PLoS Med. 2006;3:e237.

Thompson HL, Smithey MJ, Surh CD, Nikolich-Zugich J. Functional and homeostatic impact of age-related changes in lymph node stroma. Front Immunol. 2017;8:706. 
Tian X, Li C, Huang A, Xia S, Lu S, Shi Z, et al. Potent binding of 2019 novel coronavirus spike protein by a SARS coronavirus-specific human monoclonal antibody. BioRxiv. 2020;9:382-5.

Tse GM, To KF, Chan PK, Lo AW, Ng KC, Wu A, et al. Pulmonary pathological features in coronavirus associated severe acute respiratory syndrome (SARS). J Clin Pathol. 2004;57:260-5.

van den Brink EN, Ter Meulen J, Cox F, Jongeneelen MA, Thijsse A, Throsby M, et al. Molecular and biological characterization of human monoclonal antibodies binding to the spike and nucleocapsid proteins of severe acute respiratory syndrome coronavirus. J Virol. 2005;79:1635-44.

van Doremalen N, Bushmaker T, Morris DH, Holbrook MG, Gamble A, Williamson BN, et al. Aerosol and surface stability of SARS-CoV-2 as compared with SARS-CoV-1. N Engl J Med. 2020. https://doi.org/10.1056/NEJMc2004973.

Wang C, Li W, Drabek D, Okba NMA, van Haperen R, Osterhaus $\mathrm{AD}$, et al. A human monoclonal antibody blocking SARSCoV-2 infection. BioRxiv. 2020a. https://doi.org/10.1101 /2020.03.11.987958.

Wang D, Hu B, Hu C, Zhu F, Liu X, Zhang J, et al. Clinical characteristics of 138 hospitalized patients with 2019 novel coronavirus-infected pneumonia in Wuhan, China. JAMA. 2020b. https://doi.org/10.1001/jama.2020.1585.

Wrapp D, Wang N, Corbett KS, Goldsmith JA, Hsieh CL, Abiona O, et al. Cryo-EM structure of the 2019-nCoV spike in the prefusion conformation. Science. 2020;367:1260-3.

$\mathrm{Xu} \mathrm{Z}$, Shi L, Wang Y, Zhang J, Huang L, Zhang C, et al. Pathological findings of COVID-19 associated with acute respiratory distress syndrome. Lancet Respir Med. 2020;4: $420-2$.
Yan R, Zhang Y, Li Y, Xia L, Guo Y, Zhou Q. Structural basis for the recognition of the SARS-CoV-2 by full-length human ACE2. Science. 2020;6485:420-2.

Zaki AM, van Boheemen S, Bestebroer TM, Osterhaus AD, Fouchier RA. Isolation of a novel coronavirus from a man with pneumonia in Saudi Arabia. N Engl J Med. 2012;367: 1814-20.

Zhao J, Zhao J, Perlman S. T cell responses are required for protection from clinical disease and for virus clearance in severe acute respiratory syndrome coronavirus-infected mice. J Virol. 2010;84:9318-25.

Zhao WM, Song SH, Chen ML, Zou D, Ma LN, Ma YK, et al. The 2019 novel coronavirus resource. Yi Chuan. 2020;42:21221.

Zinkernagel RM. On differences between immunity and immunological memory. Curr Opin Immunol. 2002;14:523-36.

Zu ZY, Jiang MD, Xu PP, Chen W, Ni QQ, Lu GM, et al. Coronavirus disease 2019 (COVID-19): a perspective from China. Radiology. 2020:200490. https://doi.org/10.1148 /radiol.2020200490.

Zust R, Cervantes-Barragan L, Habjan M, Maier R, Neuman BW, Ziebuhr J, et al. Ribose 2'-O-methylation provides a molecular signature for the distinction of self and non-self mRNA dependent on the RNA sensor Mda5. Nat Immunol. 2011;12: 137-43.

Publisher's note Springer Nature remains neutral with regard to jurisdictional claims in published maps and institutional affiliations. 